\title{
Vitamin B12 Deficiency in Diabetic Patients on Metformin Therapy \\ A cross-sectional study from Oman
}

Ahmed Al-Hamdi, ${ }_{1}^{1}$ Mohammed Al-Gahhafi, ${ }^{2}$ Shihab Al-Roshdi, ${ }^{3}$ Sanjay Jaju, ${ }^{4}$ Ali Al-Mamari, ${ }^{5}$ Abdulaziz M. Al Mahrezi

$$
\text { نقص فيتامين B12 لدى مرضى السكري على علاج ج الميتفورمين }
$$

أحمد الحامدي، محمد الجحافي، شهاب الروشدي، سانجاي جاجو، علي المعمري، عبدالعزيز محمود المحرزي

ABSTRACT: Objectives: This study aimed to determine the prevalence of vitamin B12 deficiency amongst diabetic patients on metformin therapy. Methods: This cross-sectional study was conducted at general clinics at the University Health Center and diabetes outpatient clinics at Sultan Qaboos University Hospital, Muscat, Oman, between January and December 2017. All Omani adults who were diagnosed with type 2 diabetes mellitus and took metformin were invited to participate in the study. The variables included in this study were age, gender, duration of diabetes, dose and duration of metformin therapy, haemoglobin and glycosylated haemoglobin level. Results: A total of 248 subjects were included (response rate $=95.4 \%)$ of which $26(10.5 \%)$ were vitamin B12 deficient and 53 (21.4\%) were borderline deficient. The mean daily dose of metformin was highest among vitamin B12 deficient group $(1,981 \pm 222 \mathrm{mg} ; P=0.004)$. Conclusion: The prevalence of vitamin B12 deficiency is considerable among diabetic patients on metformin therapy. Further research is needed to confirm the need for routine screening and monitoring.

Keywords: Type 2 Diabetes Mellitus; Prevalence; Metformin; Vitamin B12 Deficiency; Oman.

الملخص: الهدف: هدفت هذه الدراسة إلى تحديد مدى انتشار نقص فيتامين B12 بين مرضى السكري على الدئ علاج الميتفورمين. الطريقة:

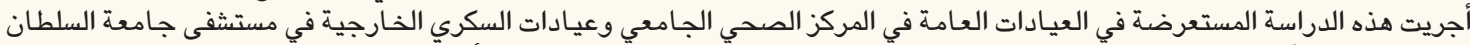

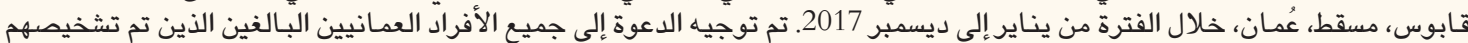

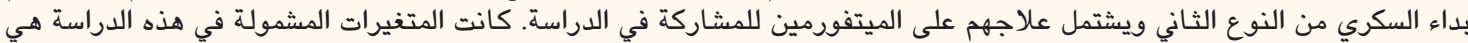

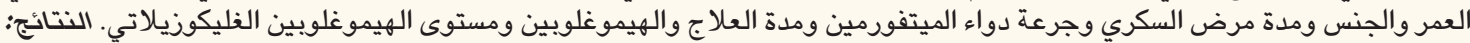

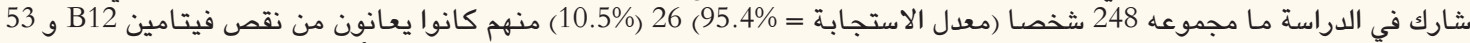

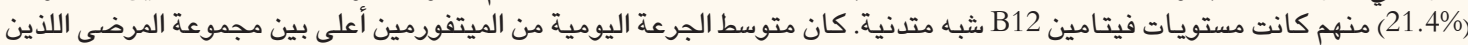

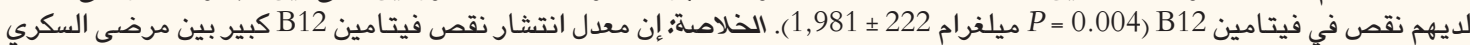
على دواء الميتفورمين. هناك حاجة إلى مزيد من البحث لتأكيد الحاجة إلى التحري الرينة الروتيني والمراقبة الدورية. الكلمات المفتاحية؛ السكري من النمط الثاني؛ مدى انتشار؛ ميتفورمين؛ نقص فيتامين B12؛ عمان.

$\mathrm{D}$ IABETES MELLITUS (DM) IS A MAJOR PUBLIC health problem affecting a large proportion of the world's population. ${ }^{1}$ Due to its chronic nature, diabetes causes devastating long-term complications.Healthcare systems worldwide are struggling to sustain the cost of care for patients with diabetes, and the financial burden is expected to increase due to the growing number of people developing the condition. Generally, the cost of care for people with diabetes is on average two to three-fold higher than for people without diabetes. ${ }^{1}$ Metformin is used globally as the first-line option for the pharmacological treatment of diabetes and is recommended by clinical practice guidelines including the American Diabetes Association (ADA) and the European Association. ${ }^{2}$
A significant decrease in the levels of serum vitamin B12 were observed in studies of patients with type 2 DM (T2DM) who were taking metformin compared to those who were not, and in studies comparing patients with T2DM taking metformin and those without T2DM. ${ }^{3-8}$ A randomised controlled trial conducted over 4.3 years reported a significant decrease in serum vitamin B12 concentration after metformin treatment. ${ }^{9}$ Patients were found to be at a higher risk of developing vitamin B12 deficiency if they took larger doses of metformin and for a longer duration. ${ }^{10}$ In such patients, early detection of vitamin B12 deficiency is important to avoid subsequent haematological and neurological manifestations. ${ }^{11}$ 
While the exact role of vitamin B12 in the pathogenesis of T2DM is still unknown, studies have indicated a possible association between vitamin B12 deficiency and serious diabetic complications such as peripheral neuropathy. ${ }^{12}$ It is hypothesised that oxidative stress is the common associated factor in both conditions. ${ }^{12}$ Therefore, screening and periodic monitoring of serum vitamin B12 could be a useful tool in any clinical guideline for diabetes.

To the best of the authors' knowledge, this is the first study in Oman to determine the prevalence of vitamin B12 deficiency in T2DM patients who are on metformin therapy and identify associated factors.

\section{Methods}

This descriptive cross-sectional study was conducted at diabetes outpatient clinics at Sultan Qaboos University Hospital (SQUH), Muscat, Oman, and general clinics at the University Health Centre, SQUH, from January to December 2017. Patients who were $\geq 18$ years of age, Omani nationals, had a diagnosis of T2DM and had been taking metformin for at least 12 consecutive months were included. Those with a history of chronic use of proton pump inhibitors or vitamin B12 supplements (either over a period of 10 consecutive months or of three prescriptions per year), pure vegetarians, a history of pernicious anaemia, chronic kidney disease, a prior gastrectomy or a prior ileectomy were excluded. All consecutive patients who fulfilled the inclusion criteria were asked to participate.

A sample size of 246 was estimated based on an absolute precision of $5 \%$ and a desired confidence level of $95 \%$ which was calculated using an initial estimate of $8 \%$ prevalence of metformin-induced vitamin B12 deficiency; this was determined from a pilot study of 60 subjects who were eventually included in the current study.

Data regarding the patients' age, gender, time since diabetes diagnosis, dose of metformin and duration of use were collected from electronic medical records. Venous blood samples were collected and sent to the laboratory to be tested for serum vitamin B12 levels, complete blood count $(\mathrm{CBC})$ and glycosylated haemoglobin (HbA1c) levels. If these tests had been conducted within the three months prior to enrolment in the study, the results were obtained from the patient's electronic medical records. HbA1c was assayed using a COBAS INTEGRA $^{\circledR} 400$ Plus (Roche Holding AG, Basel, Switzerland) which measures HbA1c concentration by a turbidimetric inhibition immunoassay in haemolysed whole blood. Serum vitamin B12 was measured using a chemiluminescent paramagnetic microparticle immuno- assay on a UniCel DxI 600 (Beckman Coulter, Inc., Brea, California, USA).

The participants were classified into three categories based on their serum vitamin B12 measurements: a deficient group $(<133 \mathrm{pmol} / \mathrm{L})$, a borderlinedeficient group (133-200 pmol/L) and a normal group $(>200 \mathrm{pmol} / \mathrm{L}){ }^{13}$ Anaemia was defined as a blood haemoglobin level of $<13 \mathrm{~g} / \mathrm{dL}$ in males and $<12 \mathrm{~g} / \mathrm{dL}$ in females. ${ }^{14}$

Data were analysed using the software Statistical Package for Social Sciences (SPSS), Version 21 (IBM, Corp., Armonk, New York, USA). Mean and standard deviation were calculated for all variables. A one-way analysis of variance was used to determine whether there were any statistically significant differences between the means of the three groups; categorical variables were analysed using the Chi-squared test. A $P$ value of $<0.05$ was considered statistically significant.

Ethical approval was obtained from the Medical Research and Ethics Committee of the College of Medicine and Health Sciences, Sultan Qaboos University, Muscat, Oman (MREC\# 1408). Informed consent was taken from all the participants.

\section{Results}

A total of 248 subjects were recruited to participate in the study (response rate $=95.4 \%$ ). The mean age of the participants was $55.3 \pm 10.0$ years and the majority of participants were female (60.5\%). The mean duration of T2DM was $6.5 \pm 4.5$ years. Vitamin B12 deficiency in metformin treated T2DM patients was found in 26 (10.5\%) participants while borderline deficiency was found in $53(21.4 \%)$ participants. The dose of metformin was higher among the vitamin B12 deficient group compared to the normal group (1981 \pm 222 versus $1695 \pm 494 \mathrm{mg} ; P=0.004$ ) [Table 1 ]. A higher proportion of those receiving metformin doses of $\geq 2000 \mathrm{mg}$ had vitamin B12 deficiency $(P=0.004)$ [Figure 1]. There was no association between the duration of metformin use and the vitamin B12 level categories. No significant associations were found between serum vitamin B12 levels and age, gender, duration of DM and haemoglobin and HbA1c levels [Table 1].

Overall, 90 (36.3\%) patients were found to be anaemic, of which 11 (42.3\%) participants were in the vitamin B12-deficient group, 15 (28.3\%) were in the borderline-deficient group and 64 (37.9\%) were in the normal group; these differences were not statistically significant [Figure 2].

Discussion 
Table 1: Characteristics and laboratory findings of participants distributed according to vitamin B12 level $(\mathrm{N}=248)$

\begin{tabular}{|c|c|c|c|c|c|}
\hline \multirow{3}{*}{ Characteristic and laboratory finding } & \multicolumn{4}{|c|}{ n (\%) } & \multirow[t]{3}{*}{$P$ value } \\
\hline & \multicolumn{3}{|c|}{ Vitamin B12 category } & \multirow[t]{2}{*}{ Total } & \\
\hline & Deficient & $\begin{array}{l}\text { Borderline- } \\
\text { deficient }\end{array}$ & Normal & & \\
\hline Total & $26(10.5)$ & $53(21.4)$ & $169(68.1)$ & $248(100)$ & - \\
\hline Age in years $\pm \mathrm{SD}$ & $56.8 \pm 11.4$ & $56.9 \pm 10.9$ & $54.6 \pm 9.5$ & $55.3 \pm 10.0$ & $\geq 0.05$ \\
\hline \multicolumn{6}{|l|}{ Gender } \\
\hline Male & $9(34.6)$ & $22(41.5)$ & $67(39.6)$ & $98(39.5)$ & \multirow{2}{*}{$\geq 0.05$} \\
\hline Female & $17(65.4)$ & $31(58.5)$ & $102(60.4)$ & $150(60.5)$ & \\
\hline Mean DM duration in years \pm SD & $6.3 \pm 3.3$ & $6.5 \pm 3.8$ & $6.6 \pm 4.8$ & $6.5 \pm 4.5$ & $\geq 0.05$ \\
\hline \multicolumn{6}{|l|}{ Daily metformin dose in $\mathrm{mg}$} \\
\hline$<2000$ & $1(3.8)$ & $9(17.0)$ & $52(30.8)$ & $62(25.0)$ & \multirow{2}{*}{0.004} \\
\hline$\geq 2000$ & $25(96.2)$ & $44(83.0)$ & $117(69.2)$ & $186(75.0)$ & \\
\hline Mean daily metformin dose in $\mathrm{mg} \pm \mathrm{SD}$ & $1981 \pm 222$ & $1849 \pm 422$ & $1695 \pm 494$ & $1758 \pm 467$ & 0.004 \\
\hline \multicolumn{6}{|l|}{ Duration of metformin use in years } \\
\hline$<4$ & $6(23.1)$ & $13(24.5)$ & $55(32.5)$ & $74(29.8)$ & \multirow{3}{*}{$\geq 0.05$} \\
\hline $4-10$ & $17(65.4)$ & $32(60.4)$ & $89(52.7)$ & $138(55.6)$ & \\
\hline$>10$ & $3(11.5)$ & $8(15.1)$ & $25(14.8)$ & $36(14.5)$ & \\
\hline \multicolumn{6}{|l|}{ Mean laboratory finding \pm SD } \\
\hline $\mathrm{HGB}$ in $\mathrm{g} / \mathrm{dL}$ & $12.0 \pm 1.5$ & $12.7 \pm 1.5$ & $12.5 \pm 1.6$ & $12.5 \pm 1.6$ & $\geq 0.05$ \\
\hline $\mathrm{MCV}$ in $\mathrm{fL}$ & $73.6 \pm 7.0$ & $74.8 \pm 7.5$ & $74.6 \pm 7.1$ & $74.5 \pm 7.2$ & $\geq 0.05$ \\
\hline HbA1c in \% & $7.2 \pm 1.2$ & $7.9 \pm 1.8$ & $8.1 \pm 1.9$ & $7.9 \pm 1.9$ & $\geq 0.05$ \\
\hline
\end{tabular}

$S D=$ standard deviation; $D M=$ diabetes mellitus; $H G B=$ haemoglobin; $M C V=$ mean corpuscular volume; HbAlc=glycosylated haemoglobin .

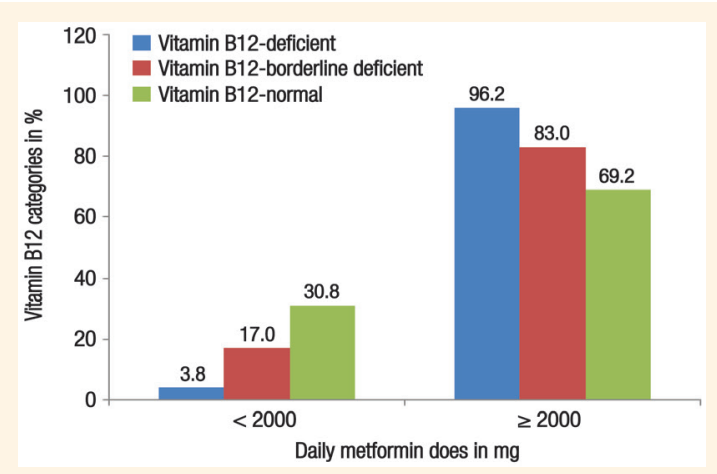

Figure 1: The relationship between vitamin B12 level and the daily dose of metformin.

This study found a high prevalence of abnormal vitamin B12 levels among Omani T2DM patients who were on metformin therapy, an association between high metformin dose and vitamin B12 deficiency and a high prevalence of anaemia. The prevalence of vitamin B12 deficiency observed in this study is similar to previous studies but others have reported variable rates. ${ }^{2,3,6-8,10}$ For example, Beulens et al. reported a prevalence of $28.1 \%$ among metformin-treated patients in a cross-sectional study of 550 subjects. ${ }^{8}$

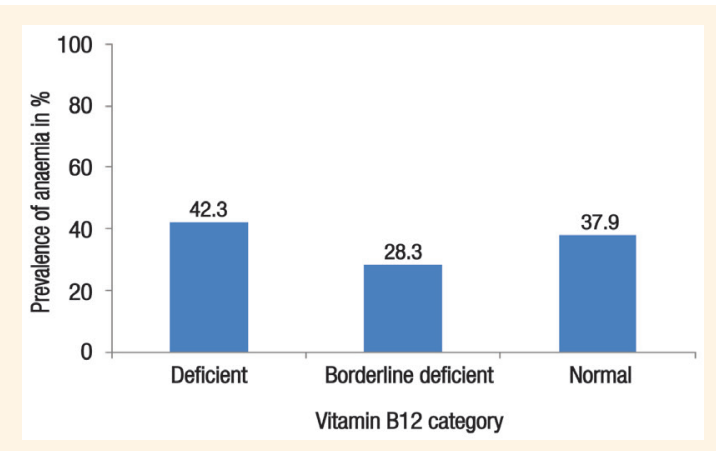

Figure 2: Prevalence of anaemia among the study population distributed according to vitamin B12 category.

A study in an elderly population who lived in longterm institutions reported a prevalence of $53.2 \%{ }^{3}$ Conversely, Aroda et al. and the National Health and Nutrition Examination Survey reported a much lower prevalence of $4.3 \%$ and $5.8 \%$, respectively. ${ }^{6,7}$ Such variation in the prevalence rates could be attributed to differences in the cut-off values for vitamin B12 deficiency, patient characteristics, dietary habits, clinical settings and laboratory measurements.

While most studies, including meta-analysis 
reviews, agree that there is an association between vitamin B12 deficiency and the intake of metformin in T2DM patients, a small number of studies have disputed this relationship. ${ }^{4,5,15,16}$ The current study confirmed the association between a high metformin dose and vitamin B12 deficiency as concluded by previous studies. ${ }^{3,10}$ Patients were found to be at a higher risk of developing vitamin B12 deficiency if they took a larger dose of metformin (>2000 mg/day) and for a longer duration ( $>4$ years). ${ }^{10}$ Another study reported a higher risk with a smaller dose $(\geq 1500 \mathrm{mg} /$ day $)$ and a shorter duration ( $>2$ years). ${ }^{3}$ However, in the current study, no association was found between the duration of metformin therapy and vitamin B12 deficiency. This finding is similar to a study conducted in the Netherlands in which the dose of metformin, but not the duration, was associated with vitamin B12 deficiency. ${ }^{8}$

Studies have reported conflicting findings regarding the consequences of vitamin B12 deficiency in T2DM patients. ${ }^{6,10,11}$ Hendrawati et al. reported higher proportions of neuropathy symptoms and haematologic abnormalities among patients who took metformin for a longer period of time ( $>3$ years versus $1-3$ years). ${ }^{11}$ Aroda et al.'s large cohort study of 2,155 participants found a higher prevalence of neuropathy and anaemia in the metformin group compared to the placebo group. ${ }^{6}$ On the other hand, Alharbi et al's study found no significant differences in the prevalence of peripheral neuropathy between metformin users and non-metformin users. ${ }^{10}$

Anaemia was highly prevalent in this study's population but there was no significant association with vitamin B12 levels. Moreover, no significant differences were found in the levels of the mean corpuscular volume among the participants. Similarly, Aroda et al. reported a high prevalence of anaemia in the metformin group but no association with vitamin B12 status. ${ }^{6}$ Anaemia is considered as a common problem in diabetic patients and is mainly attributed to iatrogenic causes, which include oral hypoglycaemic drugs and renal insufficiency. ${ }^{17}$

The limitations of this study are its descriptive nature and the lack of a control group, which does not allow for any comparison or to come to any conclusions about a causal relationship. The study was conducted in a university setting which limits the generalisability of the findings to other settings in Oman. However, despite these limitations, this study provides valuable data as it is the first to examine vitamin B12 deficiency in Omani T2DM patients on metformin therapy. An additional limitation, is that biomarkers of metabolic vitamin B12 deficiency such as methylmalonic acid, folate and homocysteine were not measured which may have resulted in underestimation of the prevalence rate.

\section{Conclusion}

The prevalence of vitamin B12 deficiency in diabetic adult Omanis on metformin therapy is considerable. The risk of developing vitamin B12 deficiency was noted to be higher among patients on high doses of metformin. Further studies with a stronger research design and utilisation of biomarkers of metabolic vitamin B12 deficiency are needed to confirm these findings and determine the need for routine screening and regular monitoring of vitamin B12 levels in such patients.

\section{CONFLICT OF INTEREST}

The authors declare no conflicts of interest.

\section{FUNDING}

This study was funded by the Dean of the College of Medicine \& Health Sciences, Sultan Qaboos University, Muscat, Oman (IG/MED/DEAN/17/01).

\section{References}

1. International Diabetes Federation. IDF Diabetes Atlas 8th Edition. From: https://www.idf.org/e-library/epidemiologyresearch/diabetes-atlas/134-idf-diabetes-atlas-8th-edition. html. Accessed: Oct 2019.

2. Ko SH, Ko SH, Ahn YB, Song KH, Han KD, Park YM, et al. Association of vitamin B12 deficiency and metformin use in patients with type 2 diabetes. J Korean Med Sci 2014; 29:965-72. https://doi.org/10.3346/jkms.2014.29.7.965.

3. Wong CW, Leung CS, Leung CP, Cheng JN. Association of metformin use with vitamin B12 deficiency in the institutionalized elderly. Arch Gerontol Geriatr 2018; 79:57-62. https://doi.org/10.1016/j.archger.2018.07.019.

4. Chapman LE, Darling AL, Brown JE. Association between metformin and vitamin B12 deficiency in patients with type 2 diabetes: A systematic review and meta-analysis. Diabetes Metab 2016; 42:316-27. https://doi.org/10.1016/j.diabet.2016.03.008.

5. Yang W, Cai X, Wu H, Ji L. Associations between metformin use and vitamin B12 levels, anemia, and neuropathy in patients with diabetes: A meta-analysis. J Diabetes 2019; 11:729-43. https://doi.org/10.1111/1753-0407.12900.

6. Aroda VR, Edelstein SL, Goldberg RB, Knowler WC, Marcovina SM, Orchard TJ, et al. Long-term metformin use and vitamin B12 deficiency in the Diabetes Prevention Program Outcomes Study. J Clin Endocrinol Metab 2016; 101:1754-61. https://doi. org/10.1210/jc.2015-3754.

7. Reinstatler L, Qi YP, Williamson RS, Garn JV, Oakley GP Ir. Association of biochemical B12 deficiency with metformin therapy and vitamin B12 supplements: The National Health and Nutrition Examination Survey, 1999-2006. Diabetes Care 2012; 35:327-33. https://doi.org/10.2337/dc11-1582.

8. Beulens JW, Hart HE, Kuijs R, Kooijman-Buiting AM, Rutten GE. 
Influence of duration and dose of metformin on cobalamin deficiency in type 2 diabetes patients using metformin. Acta Diabetol 2015; 52:47-53. https://doi.org/10.1007/s00592-0140597-8.

9. de Jager J, Kooy A, Lehert P, Wulffelé MG, van der Kolk J, Bets D, et al. Long term treatment with metformin in patients with type 2 diabetes and risk of vitamin B-12 deficiency: Randomised placebo controlled trial. BMJ 2010; 340:c2181. https://doi. org/10.1136/bmj.c2181

10. Alharbi TJ, Tourkmani AM, Abdelhay O, Alkhashan HI, AlAsmari AK, Bin Rsheed AM, et al. The association of metformin use with vitamin B12 deficiency and peripheral neuropathy in Saudi individuals with type 2 diabetes mellitus. PLoS One 2018; 13:e0204420. https://doi.org/10.1371/journal.pone.0204420.

11. Hendrawati YD, Andrajati R, Supardi S, Ariyani A. The risk of cobalamin deficiency symptoms related to long-term metformin use in T2DM patients. Acta Endocrinol (Buchar) 2018; 14:49-54. https://doi.org/10.4183/aeb.2018.49.

12. Valdés-Ramos R, Guadarrama-López AL, Martínez-Carrillo BE, Benítez-Arciniega AD. Vitamins and type 2 diabetes mellitus. Endocr Metab Immune Disord Drug Targets 2015; 15:54-63. https://doi.org/10.2174/1871530314666141111103217.

13. Yetley EA, Pfeiffer CM, Phinney KW, Bailey RL, Blackmore S,
Bock JL, et al. Biomarkers of vitamin B-12 status in NHANES: A roundtable summary. Am J Clin Nutr 2011; 94:S313-21. https://doi.org/10.3945/ajcn.111.013243.

14. World Health Organization. Diagnosis and management of iron-deficiency anaemia. Geneva: World Health Organization. WHO/NMH/NHD/MNM/11.1. P. 3.

15. Rodríguez-Gutiérrez R, Montes-Villarreal J, Rodríguez-Velver KV, González-Velázquez C, Salcido-Montenegro A, ElizondoPlazas A, et al. Metformin use and vitamin B12 deficiency: Untangling the association. Am J Med Sci 2017; 354:165-71. https://doi.org/10.1016/j.amjms.2017.04.010

16. Elhadd T, Ponirakis G, Dabbous Z, Siddique M, Chinnaiyan S, Malik RA. Metformin use is not associated with B12 deficiency or neuropathy in patients with type 2 diabetes mellitus in Qatar. Front Endocrinol (Lausanne) 2018; 9:248. https://doi. org/10.3389/fendo.2018.00248.

17. Angelousi A, Larger E. Anaemia, a common but often unrecognized risk in diabetic patients: A review. Diabetes Metab 2015; 41:18-27. https://doi.org/10.1016/j.diabet.2014.06.001. 